\title{
Il-17 and Its Role in Psoriasis, Hidradenitis Suppurativa And Acne
}

Skroza N, Proietti I, Bernardini N, Aquila E, Balduzzi V, La Viola G, Mambrin A, Muscianese M, Tolino E, Zuber S, Potenza C Elena Sofia Manca and Paolo Ferrazza

Department of Medical-Surgical Sciences and Biotechnologies, Faculty of Pharmacy and Medicine, Sapienza University of Rome-Polo Pontino, Rome, Italy

\section{Introduction}

IL-17 is a relatively recently identified cytokine involved in different inflammatory pathways. It refers to a family of six cytokines, from IL-17A to IL-17F, mainly produced by $\mathrm{T}$ helper 17 cells, a distinct $\mathrm{T}$ helper subset. Th17 cells in addition also produce IL-21 and IL-22. IL-17 thanks to its ability in neutrophile recruitment, Th2 stimulation, macrophages production of IL- $1 \beta$ and TNF- $\alpha$ and matrix metalloproteinases (MMPs) induction, plays a key role in immune responses. Upregulation of IL-17 has been linked to the pathogenesis of several chronic inflammatory and autoimmune diseases. Herein, we review IL-17 role in inflammation, focusing on its involvement in three common dermatologic diseases: psoriasis, hidradenitis suppurativa and acne.

\section{Objectives}

The primary objective of this investigation was to review existing research on the effect of IL-17 in chronic inflammatory and autoimmune disease.

This involved investigating:

- IL-17 in psoriasis

- IL-17 in acne and hidradenitis suppurativa

\section{Materials and methods}

An extensive literature search was undertaken. The main reference source was the site https://www.ncbi.nlm.nih.gov/pubmed/, which provided access to the most recent publications.

The key words used for this research are: IL-17; Psoriasis, Acne, Hidradenitis Suppurativa; IL-17 and inflammation, IL-17 and autoimmune disease.

The information obtained from this literature search was supplemented by personal discussions with key Department.

Finally, a workshop involving key Department staff was held. The workshop discussed the reasons for collecting information on public opinion, the current state of that information, and the future information needs of the Department. These discussions identified key areas for future research in this area, forming part of the recommendations made in this report.

\section{Qualitative and Quantitative methods}

Qualitative method is the process of collecting qualitative and mixed-method research data, and then writing conclusions regarding the collective results of the research.
Quantitative method is the process of collecting quantitative data to explain, predict or control effect through specific analysis of the collective results of the research.

To review the effect of IL-17 on Psoriasis, Acne and Hidradenitis Suppurativa 125 publications have been collected.

87 publications have been collected as valid support for Quali/ Quantitative analysis.

38 publications have been collected as invalid support because obsolete or repetitive.

\begin{tabular}{|l|c|c|c|}
\hline \multicolumn{1}{|c|}{ KEY WORDS } & $\begin{array}{c}\text { COLLECTED } \\
\text { PUBLICATIONS }\end{array}$ & $\begin{array}{c}\text { VALID } \\
\text { PUBLICATIONS }\end{array}$ & $\begin{array}{c}\text { INVALID } \\
\text { PUBLICATIONS }\end{array}$ \\
\hline $\begin{array}{l}\text { IL-17 and Psoriasis } \\
\text { IL-17 and Acne } \\
\text { Hidradenitis Suppurativa IL- } \\
17 \text { and inflammation, IL-17 } \\
\text { and autoimmune disease }\end{array}$ & 125 & 87 & 38 \\
\hline
\end{tabular}

\section{Il - 17 and its role in psoriasis and acne}

IL-17 is a cytokine firstly described in 1993 in rodents and named cytotoxic T lymphocyte-associated antigen (CTLA8) [1]. Subsequently, CTLA8 was discovered in human and named IL-17 [2]. In 1996 it has been found that IL-17 can stimulate the production of IL- 6 and IL-8 from synoviocytes in patients affected by rheumatoid arthritis and since then IL-17 has been linked to inflammation through IL-6 and neutrophil recruitment by IL-8 [3].

Further studies found out that he IL-17 family consists of six members, from IL-17A to IL-17F [4] even if the term IL-17 usually refers to IL-17A [5]. All the family members share some activities: IL17A, IL-17F and their heterodimers IL-17A/F have inflammatory effect with different strength, IL-17B, IL-17C, IL-17D are proinflammatory with unknown role [6]. The IL-17E cytokine, also named IL-25, is involved in Th2 cells response [7].

In the same way, the receptor family consists of five subunits, from IL-17RA to IL-17RE [7]. All these members have a single transmembrane domain and an extracellular binding domain [6].

Correspondence to: Paolo Ferrazza, Department of Medical-Surgical Sciences and Biotechnologies, Faculty of Pharmacy and Medicine, Sapienza University of Rome-Polo Pontino, Rome, Italy

Received: October 06, 2017; Accepted: October 12, 2017; Published: October 20, 2017 
The interaction between the ligand and the receptor activates different pathways: TNF receptor-associated factor (TRAF)6dependent and TRAF6-independent. The TRAF6-dependent downstream signal leads to activation of NF- $\kappa B$ and to transcription of pro-inflammatory genes [6].

Production of IL-17 is mainly operated by Th17, a T cells subset different from Th1 and Th2 cells subset, firstly described in mouse in 2005 [8]. CD8+ T cells, gd T cells, invariant natural killer $\mathrm{T}$ cells (iNKT), natural killer (NK) cells, natural Th17 cells, lymphoid tissue inducer (LTi) cells, and group 3 innate lymphoid (ILC3) cells can also release IL-17 [9].
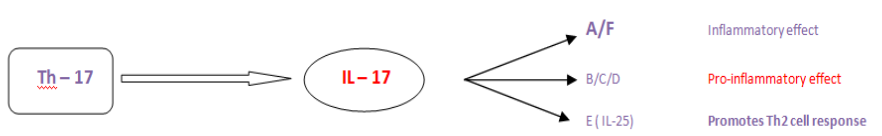

IL-17 exerts many physiological functions including: neutrophil recruitment, Th2 stimulation to provide an effective response against extracellular organisms (fungal and bacterial), macrophages production of IL- $1 \beta$ and TNF- $\alpha$ and inflammatory mediators matrix metalloproteinases (MMPs) induction [9]. Despite of the important role of IL-17 cytokine, Th17 and other IL-17 secreting cells in regulating adaptive and innate immune systems [10], its overproduction could be involved in several chronic inflammatory diseases.

In recent years, different studies have tried to associate the IL-17 pathway to an increasing number of inflammatory diseases: asthma, chronic obstructive pulmonary disease (COPD), lupus, polymyalgia rheumatica, giant cell arteritis, Behçet disease, dry-eye syndrome, and Sjögren's syndrome, Crohn's disease, Multiple sclerosis. However, the role of IL-17 in this pathology's list in still unclear [11].

Contrarily, the role of IL-17 in psoriasis is well know and different trials for IL-17 and IL-17R inhibitors have been carried out or still ongoing [12]. In the attempt to contribute to the description of the relationship between IL-17 pathways and the most frequent or emergent disabling dermatological disease, we report the state of the art about the IL-17 role in the psoriasis, acne and hidradenitis suppurativa pathways.

\section{Il-17 and psoriasis}

Psoriasis is a common chronic immune-mediated inflammatory skin disease with a prevalence ranging from $0,5 \%$ to $3 \%$ worldwide [13] Chronic plaque-type is the widespread type of psoriasis and it is characterized by the presence of localized and well demarcated erythema and scaling in characteristics body areas associated to epidermal hyperplasia [14].

The aetiology is multifactorial with genetic factors as well as extrinsic factors playing important roles. Despite in the past psoriasis was counted among the intrinsic keratinocytes abnormalities [15] and treated with methotrexate [16], in the last 40 years this statement has been revisited. In fact, the evidence of beneficial effects of cyclosporine and denileukin diftitox (toxical agent for $\mathrm{T}$ lymphocytes) on psoriasis and psoriatic arthritis has led to the hypothesis of psoriasis as immunological disease [17]. In 1990s the attention shifted from T lymphocytes to TNF- $\alpha$ and, as a consequence, TNF- $\alpha$ blocking medications were found to be very useful [18]. In recent years, Th17 cells and their most important secreted cytokine IL-17 has gained the attention of scientific communities [19].

The latest hypothesized pathogenic cascade requires the activation of dendritic cells by cutaneous pathogens and/or by DNA or RNA from damaged keratinocytes complexes with LL37 which leads to IL23 secretion from dendritic cells itself. The increase of IL-23 promotes the proliferation of Th17 which release high amounts of IL-17, IL-21 and IL-23 and the secretion of IL-17 from other tissue resident cell type (ILC3, NKT and $\gamma \delta \mathrm{T}$ ). The IL-17 binding to its receptor (IL-17R) expressed by keratinocytes promoting the aberrant differentiation and proliferation of keratinocytes, the expression of chemokines (CXCL1, CXCL2 and CCL20) which enhance recruitment of Th17 and dendritic cells to the skin, the expression of antimicrobial peptides including $\beta$ defensins and S100A family and reducing expression of cell adhesion molecules, results in disruption of skin barrier function [5].

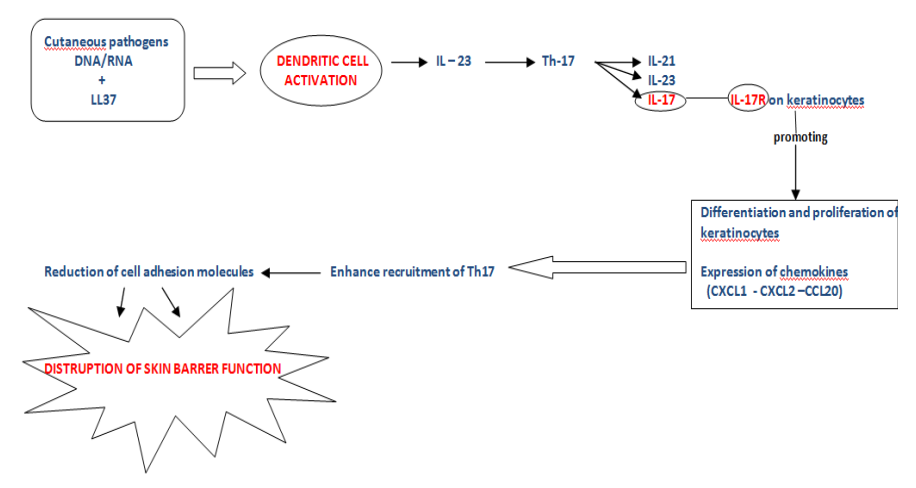

Liang et al. [20] support the emergent role of IL-17 in psoriasis pathogenesis proving its effects on keratinocytes cultures to increase the expression of antimicrobial peptides (e.g. S100) and chemokines (e.g. CCL20) that activate and recruit neutrophils and T cells.

Despite racial differences, disease state and different measurement techniques could explain controversial results in relationship between IL-17 serum levels and psoriasis, [21] more recent data reported a serum increase of IL- 17 in psoriatic patients [21] Zhang et al. [22] in a recent work on a pediatric population reported a significantly higher frequency of Th17 and its cytokines in psoriatic patients blood compared with healthy controls; the authors, also, found no correlation between serum levels of IL-17 and different pediatric ages and pointed out a significantly positively relation between the increase of Th17 blood frequency and patient PASI (Psorisis Area and Severity Index). Likewise, Safen et al. [23] and Chiricozzi et al [24] in their works reported a significant correlation between IL-17 serum levels and disease severity and Yilmaz et al. [25] found a increase of IL-17 in serum of patients with $\mathrm{PASI}>10$ more than patients with $\mathrm{PASI}<10$. In recent years different authors have studied these data researching the correlation between serum levels of IL-17 or its tissue expression and the clinical subtype of psoriasis or disease state. Christophers [26] in 2008 reported the activation of Th1 related cytokines in plaque type psoriasis and the involvement of Th17 ones in more inflammatory clinical subtypes such as guttate and pustular. Differently, Lee et al. [27] found an increase tissue level of IL-17 in lesional skin biopsy samples in plaque, pustular and palmoplantar clinical subtypes and a normal concentration in biopsies from affected scalp and guttate clinical subtype. Otherwise Rho et al. [28] reported no differences between guttate and plaque clinical subtypes and the expression of Th1 or Th17 related cytokines. Only Kyriakou et al. [29] (focused on IL-17 serum levels and nail psoriasis without finding any connection. Fotiadou et al. [30] found out higher and increased IL-17A serum levels in patients with recent onset psoriasis $(<1$ month) or with a recent flare ( $<1$ month) respect to stable patients, presenting lower levels of this cytokine or its absence. Differences into IL-17 levels probably reflect 
the systemic inflammation which is well documented in psoriatic patients in the form of metabolic syndrome or diabetes [31] or as an increased prevalence of cardiovascular diseases [32]. Coimbra et al [33] described reducing the length of remission after NB-UVB, PUVA and topical therapy in psoriatic patients with both metabolic syndrome and persistent high levels of IL-17.

In order to explain the role of IL-17 in increasing prevalence of cardiovascular diseases, is usefull to highlight the work of Karbach et al. This work shows that IL-17 overexpression at keratinocytes level induces systemic vascular inflammation, endothelial dysfunction and arterial hypertension leading to increased mortality in mice [34] On the other hand, Torres et al. [35] have recently highlighted the dual role of IL-17 in atherosclerosis. This cytokine has a pro-atherogenic effect next to stabilizing the atherosclerotic plaque by increasing the production of smooth muscle cells and collagen [36] and, also, has a role in controlling the post infarct remodelling [37]. These protective effects on the cardiovascular system could lead to avoiding IL-17 inhibitors but data about their safety are reassuring and increase of cardiovascular events has not been reported in clinical trials [38].

In conclusion, thanks to all the data and the references given above, describing and supporting the roles of IL-17 in psoriasis pathogenesis, in its different clinical subtypes and also in the presence of its most common comorbidities; the revolutionary effect of IL-17 [39] and anti IL-17R [40] medication in treating psoriasis can be easily understood.

\section{Il-17 and hidradenitis suppurativa}

Hidradenitis suppurativa (HS), also known as acne inversa, is a recurrent devastating skin disease with a prevalence of about $1 \%$ in general population [41], affecting sites rich in apocrine glands. Hidradenitis suppurativa appears with tender subcutaneous nodules and abscesses usually restricted to the intertriginous areas [42]. Disease progression is characterized by follicular occlusion, inflammation and rupture of the pilosebaceous unit, followed by a profound inflammatory response $[43,44]$ The pathogenesis of HS is not completely understood. Recent research focused on the inflammatory mechanisms involved in HS suggesting a key role for immune dysregulation in disease etiology. TGF $\beta$, IL- 6 , IL-21, and IL-23 $[45,46]$ mediate the differentiation and expansion of a subset of CD4+ T helper (Th) cells termed Th17 cells, which play a role in various inflammatory diseases including psoriasis, autoimmune uveitis, juvenile diabetes and multiple sclerosis $[47,48]$. However, it is not clear if other elements drive the differentiation of Th17 cells. Th17 are distinct from Th1 and Th2 cells, in fact both IFN $\gamma$ and IL-4, that are involved in Th1 and Th2 differentiation, negatively regulate the differentiation into Th17. These cells produce mainly interleukin 17 (IL-17A) and promote other proinflammatory cytokine and chemokine expression (such as IL-22 and IL-21 [47] IL6, GCSF, GMCSF, IL-1 $\beta$, TGF $\beta$, and TNF $\alpha$ ) by keratinocytes [48]. Other cell types such as neutrophils and mast cells are also capable of producing IL-17A [49] Th17 cells may be partly responsible for the excessive neutrophilic inflammation and purulent drainage seen in primary and secondary lesions of HS [50]. IL-17 exerts a variety of pro-inflammatory effects on the skin, including the chemotaxis of monocytes and neutrophils, the recruitment of Th17 and myeloid cells, and further increase IL-17 production and immune-cell infiltrations in HS lesions [51]. IL-22 is described in literature for its effects on keratinocytes, stimulating their hyperproliferation, epidermal acanthosis and further enhancing the antimicrobial peptides expression [52]. Several studies described alterations of the innate immune system in HS; other research postulated functional defects of neutrophils and monocytes in patients with hidradenitis suppurativa instead $[53,54]$
Interleukin (IL)-17 and IL- $1 \beta$ are upregulated in the lesional skin of patients with HS. Schlapbach et al. [51]. investigated the expression and cellular source of IL-12, IL-23, and IL-17 in lesional skin of HS by semiquantitative real-time polymerase chain reaction (RT-PCR) and immunohistochemistry. They reported that IL-23 was highly expressed in HS lesions and plays a central role in the regulation of Th17 cells, as well as IL-17 was significantly induced in lesional skin compared to normal skin. On the other hand, the immunohistochemical analysis of serial tissue sections of lesional and healthy skin showed a clear infiltration by IL-17 producing cells in lesional skin if compared with healthy one, in both papillary (P\.0001) and reticular dermis $(\mathrm{P} \backslash .0001)$ confirming the PCR results.

Van der Zee et al. [43] in en vivo and ex vivo study compared the cytokine levels released by lesional HS skin biopsies after $24 \mathrm{~h}$ of culture with that of healthy skin from controls. This comparison showed that levels of IL-1 $\beta$, TNF- $\alpha$ IL- 6 and IL-17 were elevated in HS lesions. Although several studies have proved the presence of IL-17 and Th17 cells in HS lesions, many of these have been restricted only to lesional skin. Kelly et al. [51] reported the cytokines expression in lesional skin and non lesional skin instead. They showed that the mRNA expression of IL17A, IL1 $\beta$, TNF $\alpha$ and IL10 is enhanced in hidradenitis suppurativa. The expression of both IL1 $\beta$ and IL17A was significantly enhanced in perilesional skin from HS patients compared with healthy control skin. In addition, they showed a significant enhancement of IL17A in uninvolved skin of patients with HS $10 \mathrm{~cm}$ away from any lesional activity. Based on these data, the abnormal expression of IL17 and its associated cytokine such as TNFa and IL1 $\beta$, IL6 and IL23 detected in lesional skin and both in perilesional and uninvolved skin, suggested that subclinical inflammation is present in HS skin prior to the formation of active lesions and support the idea that Th17 may participate in lesion development. In the same study the authors also examined the cellular derivation of IL- 17 in HS lesions by flow cytometry and identified classic CD4+ T cells as the source of IL-17, instead CD11c+ CD1a-CD14+ inflammatory dermal dendritic cells were involved in IL-1b production. Similarly to this study, Lima et al. [55] investigated the distribution and cellular source of IL-17 in HS analysing the in situ expression of this cytokine in lesional and perilesional skin. Additionally, to evaluate differences between early and late stages of the disease, they studied infiltrating leucocyte subsets in perifollicular and deep cells infiltrates by immunohistochemistry. They demonstrate that the number of interleukin-17+ cells is significantly increased in lesional and perilesional skin with homogeneously distribution in the papillary dermis. In particular, in the perifollicular region single cells showed a strong positivity for IL-17 while the deep infiltrate was characterized by numerous weakly positive cells. To confirm and to clarify these evidences they performed an immunofluorescence microscopy with double labelling for IL-17 and either CD4 or myeloperoxidase (as markers for lymphocytes or neutrophils, respectively). The cells with strong immunolabelling for IL-17 located in perifollicular papillary dermis could be classified as Th17 cells, while deep cells infiltrations turned out to be neutrophils. Considering the high number of neutrophils in deep dermal infiltrate of HS skin, especially in later stages of the disorder; hidradenitis suppurativa may be included in the group of neutrophilic dermatoses $[56,57]$. In literature, the cytokine pattern has been studied in lesional and non lesional HS skin, as discussed above, and in lesional secretions too. In fact Kanni et al. [58] have shown that pus derived from lesions of patients with HS contains high concentrations of pro-inflammatory cytokines (IL-17,TNFa, IL-1 $\beta$, IL-1 $\alpha$,) and of anti-inflammatory cytokines (IL-10 and IL-1ra). The profile of these cytokines differs considerably from patients to patients. 
In conclusion, such studies strongly support a primary role for immune dysregulation in HS and they are fundamental for the discovery of new therapeutic targets and pathways in HS. In particular the evidences of IL- $17, \mathrm{IL}-1 \beta$, and IL-23 roles [50] and their respective receptors provide a rationale for a new therapeutic approach in HS with modern antibodies and other target therapies.

\section{Il-17 and ACNE}

Acne is a common skin disorder characterized by a multifactorial pathogenesis based on four basic steps: hyper keratinization of the pilosebaceous follicles, increased sebum production, microbial intrafollicular colonization by Propionibacterium acnes (P. acnes) and inflammation [59]. The hyperkeratinization is caused by different factors including androgen stimulation, decreased linoleic acid and increased IL-1 $\alpha$ activity [60]. In particular, the evidence of the presence of inflammatory factors in the very earliest stages of acne lesion prior to hyper proliferation of the follicular epithelium, raises questions on the primary key role of inflammation in acne pathogenesis. Hypothesis that IL-1 $\alpha$ increased activity may be the pivotal cause of hyper proliferation of follicular keratinocytes, is supported by both its presence around uninvolved follicles preceding acne lesion development and its ability in activating the keratinocyte activation cycle [61]. Interestingly, examination of 6,24 and $72 \mathrm{~h}$ old acne lesions, revealed that CD4+ lymphocytes and CD68+ macrophages are the earliest cells that infiltrate acne lesions, while neutrophils were predominant at 24 and $72 \mathrm{~h}$ in association with the disruption of the duct, when lesions clinically correspond to pustules. Only later CD8+ cells infiltrate appears in the lesions [62]. These finding are consistent with the hypothesis that inflammation plays the key role in acne pathogenesis, in contrast to the previous view of inflammation following the disease development. The innate and adaptive Th1 cell immune responses have long been linked to acne inflammation. The involvement of Th1 cells in acne lesions is mainly due to P. acnes that can stimulate IL12 activity via Toll Like Receptor (TLR)-2, leading to the Th1-cell response activation [63]. This involvement is testified by the presence in acne lesion of high levels of Th1 polarizing transcription factor T-bet, Th1 effector cytokine IFN- $\gamma$ and Th1 type chemokine receptor CXCR [64]. Recently Th17, a subset of pro-inflammatory T helper cells defined by their production of IL-17, have been studied with increasing interest too. These cells induce tissue inflammation playing a role in the protection against bacterial infections and have been related to the pathogenesis of several autoimmune diseases and inflammatory conditions $([65,66]$. Their role in acne lesions is under investigation too. Examination of inflammatory changes in early acne lesions in two separate patient cohorts from Germany and Finland, revealed a significantly overexpression of IL-23, TGF- $\beta$ and IL-6, IL17A, IL-22, IL-26, TNF- $\alpha$, CSF2 and CCL20, which are the cytokines involved in Th17 pathways [64]. These data are consistent with the involvement of Th17/IL-17 pathway together to the already known Th1 pathway in acne pathogenesis. Agak et al. [67] confirmed these findings demonstrating the ability of $\mathrm{P}$. acnes in inducing both Th-17 and Th-1 responses as measured respectively by IL- 17 and INF- $\square$ in human peripheral blood mononuclear cells (PBMCs) in vitro, as well as the expression of key Th17 differentiation markers including ROR $\alpha$, RORc, and IL17RA and IL-17RC. Moreover at immunohistochemical examination, IL-17 expressing cells were detectable only in the epidermis of acne patients contrary to healthy skin biopsies where these cells were absent. Interestingly CD4+CD25+Foxp3+ regulatory Tcells (Tregs) cells are also significantly increased in acne lesions. This population is closely linked to Th-17 cells, indeed TGF- $\beta$ may stimulate the differentiation of both Th-17 cells and Tregs depending on the cytokines present in the environment. In particular IL-6 plays a critical role in the balance between Tregs and Th17 cells thanks to its ability in inhibiting the TGF$\beta$-driven induction of Foxp3, thus Tregs, and in stimulating the TGF$\beta$-driven development of Th17 cells from naive T cells. Consequently, the overproduction of IL- 6 leads to diseases in which Th17 cells are considered to be responsible. Intuitively, an active role in stimulating inflammation in acne lesions via multiple pathways is played by the gram-positive commensal P. acnes that colonize the pilosebaceous follicles. It stimulates both the innate and adaptive immune responses respectively via TLR- 2 and inducing Th-17 and Th- 1 differentiation. It can also stimulate antibody formation leading to the activation of the complement cascade; Moreover it produces lipases, hyaluronidases, matrix metalloproteinases and chemiotactic factors [63] P.acnes enhances Th-1 response via TLR2 inducing proinflammatory cytokines including IL-8, IL-12, IL-1b, IL12p40, IL-6, and TNF- $\alpha$ while the mechanism by which it influences Th17 is not completely understood. In response to P. acnes IL- $1 \beta$, IL- 6 and TGF- $\beta$ are the three critical cytokines for triggering the differentiation programs of naïve CD4+ T cells to Th-17 cells, that are elicitated. The major hypothesis expected that inflammation in acne can be initiated by a P. acnes-specific CD4+ T cell response [67-69]. It has been suggested that immunogenic P. acnes proteins released into the follicle by Langerhans cells after processing, could, in turn present these antigens to activated naïve CD4+ T cells in local lymph nodes with subsequent migration of Th17 back to skin [70]. Finally different studies have demonstrated that retinoic acid (RA), the active metabolite of vitamin A, successfully used in the treatment of severe acne forms, induces Tregs and downregulates the expression of genes required for Th17 cells development and differentiation such as IL-17, RORa and RORc [71,72].

In conclusion all the data and the references given above describe and support the roles of IL-17 with increased activity in the hyper proliferation of follicular keratinocytes that causes Acne.

\section{Conclusions}

Despite IL-17 and its role in inflammatory diseases is still under study and large-scale studies are needed, recent data support the theory of the important role of IL-17 in the pathogenesis of most common and debilitating inflammatory skin diseases such as psoriasis, acne and hidradenitis suppurativa. Moreover, given the good clinical response to anti interleukins drugs in psoriasis treatment, investigations on IL17 could represent the starting point in new therapeutic approach for revolutionary treatment of both severe forms of acne and hidradenitis suppurativa.

On the basis of these studies it would be interesting to perform more researches passing through a meta-analysis of all the present literature which would combine data from multiple studies thus generating a single conclusive data and, considering also anti IL-17 therapies, would create a solid starting point for the development of clinical trials.

\section{References}

1. Rouvier E, Luciani MF, Mattéi MG, Denizot F, Golstein P (1993) CTLA-8, cloned from an activated $\mathrm{T}$ cell, bearing AU-rich messenger RNA instability sequences, and homologous to a herpesvirus saimiri gene. J Immunol 150: 5445-5456. [Crossref]

2. Yao Z, Painter SL, Fanslow WC, Ulrich D, Macduff BM, et al. (1995) Human IL-17: a novel cytokine derived from T cells. J Immunol 155: 5483-5486. [Crossref]

3. Fossiez F, Djossou O, Chomarat P, Flores-Romo L, Ait-Yahia S, et al. (1996) T cell interleukin-17 induces stromal cells to produce proinflammatory and hematopoietic cytokines. Journal of Experimental Medicine 183: 2593-2603

4. Reynolds JM, Angkasekwinai P, Dong C (2010) IL-17 family member cytokines: regulation, and function in innate immunity. Cytokine Growth Factor Reviews 21: 413 423. [Crossref] 
5. Alunno A, Carubbi F, Cafaro G, Pucci G et al. (2015) Targeting the IL-23/IL-17 axis for the treatment of psoriasis and psoriatic arthritis. Expert Opin Biol Ther 15: 17271737. [Crossref]

6. Gaffen SL (2009) Structure and signalling in the IL-17 receptor family. Nat Rev Immunol 9: 556-567. [Crossref]

7. Liu S, Song X, Chrunyk BA, Shanker S, Hoth LR, et al. (2013) Crystal structures of interleukin 17A and its complex with IL-17 receptor A. Nat Commun 4: 1888 [Crossref]

8. Bettelli E, Korn T, Kuchroo VK (2007) Th17: the third member of the effector T cell trilogy. Curr Opin Immunol 19: 652-657. [Crossref]

9. Isailovic N, Daigo K, Mantovani A, Selmi C (2015) Interleukin-17 and innate immunity in infections and chronic inflammation. J Autoimmun 60: 1-11. [Crossref]

10. Sharma J, Balakrishnan L, Datta KK (2015) A knowledgebase resource for interleukin-17 family mediated signalling. J Cell Commun Signal 9: 291-196. [Crossref]

11. Beringer A, Noack M, Miossec P (2016) IL-17 in Chronic Inflammation: From Discovery to Targeting. Trends Mol Med 22: 230-241. [Crossref]

12. Canavan TN, Elmets CA, Cantrell WL, Evans JM, Elewski BE (2016) Anti-IL-17 Medications Used in the Treatment of Plaque Psoriasis and Psoriatic Arthritis: A Comprehensive Review. Am J Clin Dermatol 17: 33-47. [Crossref]

13. Campa M, Mansouri B, Warren R, Menter A (2015) A Review of Biologic Therapies Targeting IL-23 and IL-17 for Use in Moderate-to-Severe Plaque Psoriasis. Dermatol Ther 6:1-12 [Crossref]

14. Boehncke WH (2015) Etiology and Pathogenesis of Psoriasis. Rheum Dis Clin North Am 41: 665-675. [Crossref]

15. Voorhees JJ (1977) Pathophysiology of psoriasis. Annu Rev Med 28: 467-473. [Crossref]

16. McDonald CJ, Bertino JR (1969) Parenteral methotrexate in psoriasis. A report on the efficacy and toxicity of long-term intermittent treatment. Arch Dermatol 100: 655-668. [Crossref]

17. Müller W, Graf U (1981) The treatment of psoriasis-arthritis with cyclosporin A, a new immunosuppressive agent]. Schweiz Med Wochenschr 111: 408-413. [Crossref]

18. Uyemura K, Yamamura M, Fivenson DF, Modlin RL, Nickoloff BJ (1993) The cytokine network in lesional and lesion-free psoriatic skin is characterized by a T-helper type 1 cell-mediated response. J Invest Dermatol 101: 701-705. [Crossref]

19. Weaver CT, Hatton RD, Mangan PR, Harrington LE (2007) IL-17 family cytokines and the expanding diversity of effector T cell lineages. Annu Rev Immunol 25: 821-852. [Crossref]

20. Linag SC, Tan XY, Luxenberg DP, Karim R, Dunussi JK, et al. (2006) Interleukin (IL)22 and IL-17 are coexpressed by Th17 cells and cooperatively enhance expression of antimicrobial peptides. J Exp Med 203: 2271-2279. [Crossref]

21. Papp KA, Leonardi C, Menter A, Ortonne JP, Krueger JG, et al. (2012) Brodalumab, an anti-interleukin-17-receptor antibody for psoriasis. N Engl J Med 366: 1181-1189. [Crossref]

22. Zhang L, Li Y, Yang X, Wei J, Zhou S, et al. (2016) Characterization of Th17 and FoxP3(+) Treg Cells in Paediatric Psoriasis Patients. Scand J Immunol 83: 174-180. [Crossref]

23. Sofen H, Smith S, Matheson RT (2014) Guselkumab (an IL-23-speci- fic mAb) demonstrates clinical and molecular response in patients with moderate-to-severe psoriasis. J Allergy Clin Immunol 133: 1032-1040. [Crossref]

24. Chiricozzi MF, Fuentes DJ, Cueto I, Li K, Tian S, et al. (2016) Increased expression of interleukin-17 pathway genes in nonlesional skin of moderate-to-severe psoriasis vulgaris. Br J Dermatol 174: 136-145. [Crossref]

25. Yilmaz SB, Cicek N, Coskun M, Yegin O, Alpsoy E (2012) Serum and tissue levelsof IL-17 in different clinical subtypes of psoriasis," Arch Dermatol Res 304: 465-469. [Crossref]

26. Christophers E (2008) Explaining phenotype heterogeneity in patients with psoriasis. Br J Dermatol 158: 437-441. [Crossref]

27. Lee E, Zarei M, LaSenna C, Villada G, Romanelli P (2015) Psoriasis Targeted Therapy: Characterization of Interleukin 17A Expression in Subtypes of Psoriasis. J Drugs Dermatol 14: 1133-1136. [Crossref]

28. Roh NK, Han SH, Youn SJ, Kim JR, Lee YW, et al. (2015) Tissue and Serum Inflammatory Cytokine Levels in Korean Psoriasis Patients: A Comparison between Plaque and Guttate Psoriasis.” Ann Dermatol 27: 738-743. [Crossref]
29. Kyriakou, Patsatsi A, Vyzantiadis TA, Sotiriadis D (2014) Serum levels of TNF-a IL-12/23 p40, and IL-17 in Psoriatic Patients with and without Nail Psoriasis: A CrossSectional Study," Scientific World Journal.

30. Fotiadou C, Lazaridou E, Sotiriou E, Gerou S, Kyrgidis A, et al. (2015) IL-17A, IL- 22, and IL-23 as Markers of Psoriasis Activity: A Cross-sectional, Hospital- based Study. J Cutan Med Surg 19: 555-560. [Crossref]

31. Parodi, Aste N, Calvieri C, Cantoresi F, Carlesimo M, et al. (2014) Metabolic syndrome prevalence in psoriasis: a cross-sectinal study in the Italian population," Am J Clin Dermatol 15: 371-377. [Crossref]

32. Proietti, RaimondiG, Skroza N, Pampena R, Bernardini N, et al. (2014) Cardiovascular risk in psoriatic patients detected by heart rate variability (HRV) analysis. Drug Dev Res 75: 81-84 [Crossref]

33. Coimbra S, Oliveira H, Neuparth MJ, Proença JB, Figueoredo J, et al. (2016) Systemic inflammation and proinflammatory interleukin-17 signalling persist at the end of therapy in patients with metabolic syndrome and psoriasis, reducing the length of remission," Br J Dermatol 174: 414-416. [Crossref]

34. Karbach S, Croxford AL, Oelze M, Schuler R, Minwegen D, et al. (2014) Interleukin 17 drives vascular inflammation, endothelial dysfunction, and arterial hypertension in psoriasis-like skin disease, Arterioscler Thromb Vasc Biol 34: 2658-2668. [Crossref]

35. Torres T, Raposo I, Selores M (2016) IL-17 Blockade in Psoriasis: Friend or Foe in Cardiovascular Risk? Am J Clin Dermatol 17: 107-112. [Crossref]

36. Gistera, Robertson AK, Andersson J, Ketelhuth DF, Ovchin-nikova O, et al. (2013) Transforming growth factor-beta signaling in $\mathrm{T}$ cells promotes stabilization of atherosclerotic plaques through an interleukin-17-dependent pathway. Sci Transl Med 5: 190-197. [Crossref]

37. Savvatis K, Pappritz K, Becher PM, Lindner D, Zietsch C, et al. (2014) Interleukin-23 deficiency leads to impaired wound healing and adverse prognosis after myocardial infarction, Circ Heart Fail 7: 161-171. [Crossref]

38. Garnock KP (2015) Secukinumab: a review in moderate to severe plaque psoriasis," Am J Clin Dermatol 16: 323-330. [Crossref]

39. Langley RG, Elewski BE, Lebwohl M, Reich K, Griffiths CE, et al. (2014) Secukinumab in plaque psoriasis--results of two phase 3 trials. N Engl J Med 371: 326-338. [Crossref]

40. Papp KA, Reich R, Paul C, Blauvalet A, Baran W, et al. (2016) A prospective phase 3 , randomised, double-blind, placebo-controlled study of brodalumab in patients with moderate-to-severe plaque psoriasis. Br J Dermatol 175: 273-86 [Crossref]

41. Onderdijk AJ, van der Zee HH, Esmann S, Lophaven S, Dufour DN, et al. (2013) Depression in patients with hidradenitis suppurativa. J Eur Acad Dermatol Venereol 27: 473-478. [Crossref]

42. Revuz J (2009) Hidradenitis suppurativa. J Eur Acad Dermatol Venereol 23: 985-998. [Crossref]

43. Van der Zee HH, de Ruiter L, Boer L (2012) Alterations in leucocyte subsets and histomorphology in normal-appearing perilesional skin and early and chronic hidradenitis suppurativa lesions" Br J Dermatol 166: 98-106. [Crossref]

44. Laffert MV, Helmbold P, Wohlrab J, Fiedler E, Stadie V, Marsch WC (2010) Hidradenitis suppurativa (acne inversa): early inflammatory events at terminal follicles and at interfollicular epidermis". Exp Dermatol 19: 533-570[Crossref]

45. Cua DJ, Sherlock J, Chen Y, Murphy CA, Joyce B, et al. (2003) "Interleukin-23 rather than interleukin-12 is the critical cytokine for autoimmune inflammation of the brain". Nature 421: 744-800. [Crossref]

46. McGeachy MJ, Bak-Jensen KS, Chen Y, Tato CM, Blumenschein W, et al. (2007) TGF-beta and IL-6 drive the production of IL-17 and IL-10 by T cells and restrain T(H)-17 cell-mediated pathology. Nat Immunol 8: 1390-1397. [Crossref]

47. Ouyang W, Kolls JK, Zheng Y (2008) The biological functions of T helper 17 cell effector cytokines in inflammation. Immunity 28: 454-467. [Crossref]

48. Harper EG, Guo C, Rizzo H, Lillis JV, Kurtz SE, et al. (2009) Th17 cytokines stimulate CCL20 expression in keratinocytes in vitro and in vivo: implications for psoriasis pathogenesis. J Invest Dermatol 129: 2175-2183. [Crossref]

49. Lynde CW, Poulin Y, Vender R, Bourcier M, Khalil S (2014) Interleukin 17A: toward a new understanding of psoriasis pathogenesis. J Am Acad Dermatol 71: 141-150. [Crossref]

50. Schlapbach C, Hänni T, Yawalkar N, Hunger RE (2011) Expression of the IL-23/Th17 pathway in lesions of hidradenitis suppurativa. J Am Acad Dermatol 65: 790-798. [Crossref] 
51. Kelly G, Hughes R, McGarry T, van den Born M, Adamzik K, et al. (2015) Dysregulated cytokine expression in lesional and nonlesional skin in hidradenitis suppurativa" $\mathrm{BrJ}$ Dermatol 173: 1431-1439. [Crossref]

52. Di Cesare A, Di Meglio P, Nestle FO (2009) The IL-23/Th17 axis in the immunopathogenesis of psoriasis. J Invest Dermatol 129: 1339-1350. [Crossref]

53. Giamarellos-Bourboulis EJ, Antonopoulou A, Petropoulou C, Mouktaroudi M, Spyridaki E, et al. (2007) Altered innate and adaptive immune responses in patients with hidradenitis suppurativa. Br J Dermatol 156: 51-56. [Crossref]

54. Lapins J, Asman B, Gustafsson A, Bergström K, Emtestam L (2001) Neutrophil-related host response in hidradenitis suppurativa: a pilot study in patients with inactive disease" Acta Derm Venereol 81: 96-99. [Crossref]

55. Lima AL, Karl I, Giner T, Poppe H, Schmidt M, et al. (2015) Keratinocytes and neutrophils are important sources of proinflammatory molecules in hidradenitis suppurativa. Br J Dermatol 174: 514-521. [Crossref]

56. Wallach D, Vignon-Pennamen MD (2006) From acute febrile neutrophilic dermatosis to neutrophilic disease: forty years of clinical research. J Am Acad Dermatol 55: 106671. [Crossref]

57. Marzano AV, Menicanti C, Crosti C, Trevisan V (2013) Neutrophilic dermatoses and inflammatory bowel diseases. G Ital Dermatol Venereol 148: 185-196. [Crossref]

58. Kanni T, Tzanetakou V, Savva A, Kersten B, Pistiki A (2015) Compartmentalized Cytokine Responses in Hidradenitis Suppurativa. PLoS One [Crossref]

59. Toyoda M, Morohashi M (2001) Pathogenesis of acne. Med Electron Microsc 34: 2940. [Crossref]

60. Guy R, Kealey T (1998) The effects of inflammatory cytokines on the isolated human sebaceous infundibulum. J Invest Dermatol 110: 410-415. [Crossref]

61. Freedberg IM, Tomic-Canic M, Komine M, Blumenberg M (2001) Keratins and the keratinocyte activation cycle. J Invest Dermatol 116: 633-640. [Crossref]

62. Norris JF, Cunliffe WJ (1988) A histological and immunocytochemical study of early acne lesions. Br J Dermatol 118: 651-659. [Crossref]
63. Kim J, Ochoa MT, Krutzik SR, Takeuchi O, Uematsu S, et al. (2002) Activation of toll-like receptor 2 in acne triggers inflammatory cytokine responses. J Immunol 169: 1535-1541. [Crossref]

64. Kelhälä HL, Palatsi R, Fyhrquist N, Lehtimäki S, Väyrynen JP, et al. (2014) IL-17 Th17 pathway is activated in acne lesions. PLoS One 9: e105238. [Crossref]

65. Amadi-Obi A1, Yu CR, Liu X, Mahdi RM, Clarke GL, et al. (2007) TH17 cells contribute to uveitis and scleritis and are expanded by IL-2 and inhibited by IL-27/ STAT1. Nat Med 13: 711-718. [Crossref]

66. Teunissen MB, Koomen CW, de Waal Malefyt R, Wierenga EA, Bos JD (1998) Interleukin-17 and interferon-gamma synergize in the enhancement of proinflammatory cytokine production by human keratinocytes. J Invest Dermatol 111: 645-649. [Crossref]

67. Agak GW, Qin M, Nobe J, Kim MH, Krutzik SR, et al. (2014) Propionibacterium acnes Induces an IL-17 Response in Acne Vulgaris that Is Regulated by Vitamin A and Vitamin D. J Invest Dermatol 134: 366-373. [Crossref]

68. Lodes MJ, Secrist H, Benson DR, Jen S, Shanebeck KD, et al. (2006) Variable expression of immunoreactive surface proteins of Propionibacterium acnes" Microbiology 152: 3667-3681. [Crossref]

69. Farrar MD, Ingham E (2004) Acne: inflammation. Clin Dermatol 22: 380-384 [Crossref]

70. Thiboutot DM, Layton AM, Anne Eady E2 (2014) IL-17: a key player in the P. acnes inflammatory cascade? J Invest Dermatol 134: 307-310. [Crossref]

71. Xiao S, Jin H, Korn T, Liu SM, Oukka M (2008) Retinoic acid increases Foxp3+ regulatory $\mathrm{T}$ cells and inhibits development of Th17 cells by enhancing TGF-betadriven Smad3 signaling and inhibiting IL-6 and IL-23 receptor expression" J Immunol 181: 2277-2284. [Crossref]

72. Mucida D, Park Y, Kim G, Turovskaya O, Scott I, et al. (2007) Reciprocal TH17 and regulatory $\mathrm{T}$ cell differentiation mediated by retinoic acid. Science 317: 256-260. [Crossref]

Copyright: (C2017 Skroza N. This is an open-access article distributed under the terms of the Creative Commons Attribution License, which permits unrestricted use, distribution, and reproduction in any medium, provided the original author and source are credited. 